\title{
Evaluasi Program Ka Bandara (Minangkabau Ekpres) Sebagai Sarana Transportasi Publik
}

\author{
Andrisk Khairi ${ }^{1}$, Rammadani Yusran ${ }^{2 *}$ \\ ${ }^{12}$ Jurusan Administrasi Publik, Fakultas Ilmu Sosial, Universitas Negeri Padang \\ Email Coresspond: yusranrdy@ fis.unp.ac.id ${ }^{2}$
}

\begin{abstract}
This study aims to analyze the Evaluation of the Airport Train Program (Minangkabau Ekpres) based on the foundation of Law No.23 of 2014 concerning Railways and the 2030 National Railway Master Plan (RipNas2030) which explains the goals and objectives of the Airport Railway program. This research was conducted because it saw the activities of airport train passengers who were still less interested. The research method used in the study used a qualitative approach with a descriptive method. Research informants Data were collected through interviews with informants, field observations and documentation studies. The results of this study aim to determine the conditions and problems experienced by managers and complaints from researchers
\end{abstract}

Keywords : Evaluation, Analysis of managers, passengers, public police

Abstrak. Penelitian ini berttujuan untuk menganalisis Evaluasi dari Program KA Bandara (Minangkabau Ekpres) berdasarkan lamdasan UU No.23 tahun 2014 tentang Perkeretaapian dan Rancangan Induk Perkeretaapian Nasional 2030 (RipNas2030) yang menjelaskan tentang tujuan dan sasaran dari program Kereta Api Bandara. Penelitian ini dilakukan karena melihat aktivitas penumpang KA Bandara yang masih kurang peminat. Metode penelitian yang dipakai pada penelitian menggunakan pendekatankualitatif dengan metode deskriptif. Informan penelitan Data dikumpulkan lewat wawancara dengan informan, observasi di lapangan dan studi dokumentasi. Hasil penelitian ini bertujuan untuk mengetahui kondisi dan permasalahan yang dialami pihak penggelola dan keluhan dari penumpang sehingga peneliti dapat mengetahui penyebab menurutnya minat penumpang menaiki KA Bandara (Minangkabau Ekpres).

Kata Kunci : Evalausi, Analisis pengelola, penumpang, kebijakan publik

\section{PENDAHULUAN}

Dalam rangka meningkatkan pelayanan yang diberikan kepada masyarakat dan memoderisasi moda Kereta Api, Pemerintah melakukan berbagai inovasi khusunya dalam aspek pelayanan kepada masyarakat dalam rangka mengurangi beban di jalan raya, Pemerintah pusat membuat sebuah kebijakan yang berkaitan dengan pelayanan publik yaitu menghadirkan kereta Api Bandara di setiap Provinsi di indonesi. Program Kereta Api Bandara tertuang dalam UU No. 23 tahun 2007 tentang perkeretaapian dan Rencangan induk Perkeretaapian Nasional (RipNas) tahun 2030.

Adapun Implementasi KA minagkabau Ekpres tertuang dalam ripnas (rancngan induk perkeretaapian nasional) tahun 2030, di dalam ripnas terdapat UU No 23 tahun 2007 yang menjelelaskan tentang program dan tujuan transportasi kereta api ini. bahwa progran khusus Kereta Api Bandara (Kota Menuju Bandara Kota Padang) tahun 2015-2030 di mulai dari pembanguan jembatan, stasiun Duku, bandara, persinyalan dan Pembangunan overcapping Stasiun Padang. Dengan Tujuan dari program Kereta Api Bandara ini adalah untuk menaikan eksebilitas Kereta Api di Indonesia khusunya di Sumatera Barat, guna memoderinisasi moda transportasi Kereta Api serta membantu mengurangi beban kendaraan di jalan raya,serta menghadirkan moda transportasi yang bersaing dari segi finansial dan waktu serta meningkatkan kualitas pelayanan.

Dalam pembangunan KA Bandara Minangkabau Ekpres, sesuai dengan UU No.23 tahun 2007 mendorong peran pemerintah daerah untuk terlibat dalam penyelenggaraan 
perkeretaapian yang ada di daerahnya, sesuai dengan program Pemerintah Pusat pada masa pemerintahan presiden Jokowi maka dari itu Sumatera pada tahun 2015 pada masa pemerintahan Gubernur irwan prayitno mengajukan pembangunan KA bandara untuk Provinsi Sumatera Barat, dengan anggaran 187 $M$ untuk pembangunan rel untuk menuju bandara internasional minangkabau. Selain itu proyek kereta api bandara ini menghabiskan anggaran lebih kurang 200M yang di ambil dari APBN yang digunakan untuk memproduksi kereta yang dibuat oleh PT INKA serta kebutuhan lainnya.

Namun dalam Implemntasi di lapangan peneliti menemukan adanya permasalahan di lapangan, kurangnya minat masyarakat untuk menjadikan KA Bandara sabagai sarana Transportasi Publik belum dapat mencapai tujuan dalam pembangunan KA Bandara Ini adapun permasalahan yang ditemukan peneliti di lapangan adalah (1) kurangnya sarana dan prasarana (2) Stasiun KA tidak terintekritas dengan moda transportasi laiinya (3) Promosi KA bandara Belum Maksimal.

\section{METODE}

Dalam penelitian ini, peneliti menggunakan jenis penelitian kualitatif dengan metode menggunakan deskriptif. Moleong (2007:6) mengatakan bahwa penelitian kualitatif ialah penelitian yang bertujuan untuk memahami fenomena mengenai apa saja yang dialami oleh subjek penelitian secara holistik dan dengan cara deskripsi berbentuk kata-kata dan bahasa, pada suatu konteks khusus yang alamiah dan dengan memanfaatkan berbagai macam metode ilmiah. Penelitian ini dilakukan di PT.KAI Divre II Sumbar. Informan Penelitian ini menggunakan teknik purposive sampling yaitu pemilihan informan yang dilakukan dengan sengaja dan teknik snowball sampling yakni pengambilan sampel sumber data yang pada awalnya berjumlah sedikit hingga semakin besar.

Pengumpulan data awal mulai dilaksanakan pada juni 2020 sampai pada mei 2021. Jenis data yang digunakan pada penelitian ini terdiri dari data primer yaitu data utama berupa hasil dari observasi dan wamwancara dengan informan dan data sekunder berupa data pendukung atau pelengkap yang berkaitan dengan penelitian ini. Teknik pengumpulan data yang dilakukan oleh peneliti ialah menggunakan tiga metode yaitu wawancara dengan informan, observasi di lapangan, dan studi dokumentasi. Dalam menguji keabsahan data, peneliti memakai teknik triangulasi sumber yang digunakan dengan cara membandingkan data yang diperoleh dalam penelitian.

\section{HASIL DAN PEMBAHASAN}

Berdasarkan temuan dilapangan bahwa implementasi KA bandara (minangkabau ekpres) sebagai sarana transportasi melaksankan 4 tujuan dari KA Bandara Minagkabau Ekpres ini bawah ini:

\section{Untuk menunjang pemerataan, pertumbuhan, stabilitas, pendorong, dan penggerak pembangunan nasional. \\ Dalam rangka meningkat pembangunan} nasonal,Pemerintah pusat melakukan pembangunan mengeluruh di suluruh Indonesia tanpa kecuali di Sumatera Barat dengan hadirnya KA Bandara di harapkan masyarakat dapat terbantu dari segi waktu, biaya serta di jamin keamanan dan keselamatan nya dalam perjalanan.

Dalam implementasi KA Minangkabau Ekpres ini, tujuan tersebut sudah tercapai,dengan adanya KA Bandara di Sumatera Barat dapat meningkatkan pembangunan di daerah serta membantu pertumbuhan Ekonomi karna dengan adanya KA Bandara masyarakat dapat terbantu khusunya dari segi biaya dan juga waktu.

Hal ini dapat dilihat dengan adanya KA bandara masyarakat lebih banyak pilihan untuk bepergian dari dan menuju bandara, dengan harga yang mampu bersaing dengan transportasi lain, serta respons masyarakat yang menyambut baik kehadiran KA Bandara ini.adapun Tujuan dari program Kereta Api Bandara ini adalah untuk menaikan eksebilitas Kereta Api di Indonesia khusunya di Sumatera Barat, guna memoderinisasi moda transportasi Kereta Api serta membantu mengurangi beban kendaraan di jalan Raya.

Hal ini juga di dudukung oleh Dunn, (2003:437) .Keberhasilan kebijakan dapat 
dilihat melalui tanggapan masyarakat atas pelaksanaannya setelah terlebih dahulu memprediksi pengaruh yang akan terjadi jika suatu kebijakan akan dilaksanakan. Tanggapan masyarakat setelah dampak kebijakan sudah mulai dapat dirasakan baik dalam bentuk positif berupa dukungan ataupun wujud yang negatif berupa penolakan

\section{Meningkatkan keamanan kualitas dan pelayanan, perkeretaapian keselamatan}

Untuk meningkatkan kualitias pelayanan, kemanan dan keselamatan pihak pengelola melakukan pembanguan jembatan, stasiun, bandara, persinyalan dan Pembangunan overcapping Stasiun Padang dengan melakukan pembangunan sesuai dengan pedoman Induk Perkeretaapian Nasional.

Untuk meningkatkan kualitas, pelayanan, keamanan pihak mengelola sudah memfasilitasi KA Bandara dengan gerbong yang full acc, bangku yang single sett, serta bagasi untuk melekkan barang aman dan luas, untuk pembangunan stasiun baru ada penambahan yaitu Stasiun KA Bandara (BIM), Stasiun Duku, dan Stasiun Pulau Aie.

Pada tahun 2017 dilaksanakan pembangunan overcapping Stasiun Padang, peningkatan 3 (tiga) jembatan, peningkatan jalur KA Stasiun BIM Stasiun Duku termasuk bangunan pendukung, dan fasilitas pendukung operasi di Stasiun BIM, peningkatan jalan rel antara Stasiun Tabing Stasiun Duku, dan pembangunan Sistem Radio untuk mendukung operasional KA Bandara Internasional Minangkabau (KA BIM). Jalur KA Bandara Internasional Minangkabau (KA BIM) membentang sepanjang $\pm 22,7 \mathrm{Km}$ dari Stasiun Padang hingga Stasiun Bandara Internasional Minangkabau. Jalur KA sepanjang 18,8 Km merupakan jalur KA eksisting dari Stasiun Padang sampai Stasiun Duku, sedangkan jalur KA dari Stasiun Duku ke Stasiun Bandara Internasional Minangkabau sepanjang 3,9 Km adalah jalur KA baru

Dalam Implementasi nya masih banyak kendala yang di temui penulis di lapangan, seperti kondisi stasiun yang masih kurang nyaman , serta masih banyak di temui perlintas KA yang belum memakai palang pintu, sehingga sangat rawan terjadi kecelakaan sehingga akan menimbulkan keterlambatan perjalanan dan dapat merugikan pelanggan.

Berdasarkan temuan di atas, di dukung ole penelitian Santoso \& Purba,(2015:13) menyatakan bahwa masyarakat memilih menggunakan kereta api karena lebih nyaman dan dapat menghindari kemacetan, juga kereta apisekarang sudah di terdapat AC(Air Conditioner) sehingga membuat penumpang merasa lebih nyaman saat berada di dalam kereta api.

\section{Meningkatkan peran kereta api perkotaan dan kereta api antar kota}

Untuk menuju bandara internasional minangkabau , kereta api ini Memudahkan fasilitas transportasi bagi masyarakat kota padang untuk menuju ke Bandara Internasional Minangkabau dan juga melaksanakan program pemerintah pusat untuk dapat menyediakan fasilitas siap mutu untuk mengurangi kemacetan di pusat kota. Dengan adanya penambahan stasiun duku dan pulau aie maka peran KA Bandara dapat sebagai penghubung perkeretaapiam antar kota dapat terpenuhi karna melewati jalan utama perkotaan melewati tempat srategis seperti kartor, perumahan padat penduduk dan destinasi wisata yang terletak di pulau aie

Hal ini didukung oleh teori Responsifitas Menurut William N. Dunn bahwa dalam kebijakan publik berarti tanggapan sasaran kebijakan publik atas penerapan suatu kebijakan, dengan seberapa jauh suatu kebijakan dapat memuaskan kebutuhan, preferensi, atau nilai kelompok-kelompok masyarakat tertentu (Dunn, 2003:437).

Kereta Api bandara Minangkabau dapat menjangkau semua kalangan masayarakat yang ingin bepergian menuju bandara dengan nyaman, aman, cepat dan tepat waktu, dengan Harga yang sesuai dengan kondisi masyakat Sumatera Barat. Pengaruh yang di rasakan oleh masyarakat setelah adanya KA Bandara ini tentunya masyakat lebih banyak pilihan transportasi untuk menuju bandara, tetapi dalam pelaksanaan nya masyarakat khusunya di kota padang, hanya lebih penasaran dengan kelebihan yang di tawarkan oleh KA Bandara ini. Adanya penurunan penumpang 
sebelumnya, menjadi evaluasi bagi pihak pengelola maka dari itu pihak pengelola juga mengupayakan penambahan jumlah keberangkatan yang sebelumnya Cuma 10x menjadi $12 \mathrm{x}$ perjalanan, Setelah 3 bulan pengoperasian,terjadi penurunan yang signifikan dari segi penumpang, yang di mana hanya menyangkut 50\% di hari kerja dan 65$70 \%$ di hari libur.

Berdasarkan temuan di atas, didukung oleh teori William N. Dunn responsivitas (responsiveness) berkenaan dengan seberapa jauh suatu kebijakan dapat memuaskan kebutuhan, preferensi, atau nilai kelompokkelompok masyarakat tertentu (Dunn, 2003:437). Keberhasilan kebijakan dapat dilihat melalui tanggapan masyarakat atas pelaksanaannya setelah terlebih dahulu memprediksi pengaruh yang akan terjadi jika suatu kebijakan akan dilaksanakan. Tanggapan masyarakat setelah dampak kebijakan sudah mulai dapat dirasakan dapat dalam bentuk yang positif berupa dukungan ataupun wujud yang negatif berupa penolakan.Dunn pun mengemukakan bahwa kriteria responsivitas adalah penting karena analisis yang dapat memuaskan semua kriteria lainnya (efektivitas, efisiensi, kecukupan, kesamaan) masih gagal jika belum menanggapi kebutuhan aktual dari kelompok yang semestinya diuntungkan dari adanya suatu kebijakan (Dunn, 2003:437).

4. keterjangkauan (aksesibilitas) masyarakat terhadap layanan kereta api melalui mekanisme kewajiban pelayanan publik (public services obligation).

Kereta Api Bandara ini diperuntukkan untuk mampercepat penumpang/masyarakat agar sampai ditujuan dan didukung dengan fasilitas yang nyaman. Sama halnya dalam waktu tempuh perjalanan dari stasiun Simpang haru tujuan bandara dapat ditempuh dalam waktu 20-25 menit sesuai dengan jadwal kebverangkatan kereta api. Adapun fasilitas yang disediakan oleh PT. KAI ialah tentunya otomotif yang nyaman dilengkapi dengan ruangan full ac, charging dan tempat bagasi barang yang luas dan aman.

Progran khusus Kereta Api Bandara (Kota Menuju Bandara Kota Padang) tahun 2015-2030 khusus dengan program pembanguan mulai dari pembanguan jembatan, stasiun Duku, bandara, persinyalan dan Pembangunan overcapping Stasiun Padang. Dengan Tujuan dari program Kereta Api Bandara ini adalah untuk menaikan eksebilitas Kereta Api di Indonesia khusunya di Sumatera Barat, guna memoderinisasi moda transportasi Kereta Api serta membantu mengurangi beban kendaraan di jalan raya serta menghadirkan moda transportasi yang bersaing dari segi finansial dan waktu.

Berdasarkan temuan di atas, di dukung oleh Menurut (Mahmudi, 2005:92) bahwa efektifitas berfokus pada outcome (hasil) status organisasi, program, atau kegiatan yang dinilai efektif apabila output yang dihasilkan dapat memenuhi tujuan yang

Temuan lain didukung oleh pendapat Sedianingsih (2010: 20) Efektif adalah mengerjakan sesuatu yang tepat (do the right things) bagaimana agar tepat sasaran, sehingga sasaran yang diinginkan dapat tercapai dapat dikatakan bahwa sesuatu yang dikatakan efektif apabila tujuan dapat dicapai sesuai dengan yang diharapkan. Selanjutnya menurut M. As'ad (2001:47) menjelaskan bahwa setiap pekerjaan dapat dikatakan efektif ditentukan oleh pencapaian sasaran yang ditetapkan dan dengan menggunakan waktu yang dicapai. Sama halnya menurut Ratmintio dan Septi Winarsih, (2005:179) mengemukakan bahwa tercapainya tujuan yang telah ditetapkan, baik itu dalam bentuk target,tataran jangka panjang maupun misi organisasi merupakan jabaran dari defenisi efektifitas.

Kereta api murupakan salah satu moda trasportasi darat yang dapat memindahkan orang dari satu tempat ke tempat lain dengan aman, nyaman, dan cepat, sehingga kereta api bisa membantu mengurangi kepadatan di jalan raya sesuai dengan anjuran pemerintah pusat,dengan hadirnya kereta api bandara di harapkan masyarakat terbantu dari segi waktu sehingga penumpang yang ingin bepergian ke bandara bisa smpai ke tujuan dengan cepat tanpa mengalami kendala di jalan, sperti kemacetan dan kendala lainnya.

Masyarakat mendapatkan salah satu bentuk subsidi tarif kereta dimana untuk keberangkatan setiap stasiun tujuan bandara ataupun sebaliknya 
dikenakan tarif Rp. 10.000, hal ini tentunya membuat daya tarik masyarakat dalam menggunakan transportasi kereta api. Hal inin merupakan salah satu bentuk tujuan pemerintah membentuk program untuk masyarakat. Dimana memnuat masyarakat lebih tertarik untu menggunakan tranportasi umum khusunya kereta api dibandingkan transportasi pribadi. Dan juga dengan beroperasinya kereta api tujuan bandara membuat sedikit perbandingan tarif transportasi dibandingkan transportasi umum lainnya Salah satu kelebihan dari KA Bandara ini adalah harganya yang jauh lebih murah di bandingkan dengan transportasi lain, contohnya saja klau kita naik angkutan umum seperti taxi, grab, gocar, ataupun ojek, perbandingan harganya tentu $2 x$ lipat di banding naik KA bandara, untuk naik taxi kita menghabiskan ongkos sekitar Rp.40.000 sampai Rp 75.000 satu kali perjalanan, dan itu kita tidak akan di jamin ke amanan ataupun ke nyaman selama perjalanan, hal ini lah yang mejadi kelebihan yang kita miliki di Kereta Api Bandara ini, dengan hadirkannya KA bandara ini , masyarakat yang ingin bepergian menuju bandara mempunyai arternatif lain untuk bepergian menuju Bandara.

\section{KESIMPULAN}

Berdasarkan hasil penelitian yang telah di bahas sebelumnya, maka penelitian ini disimpulkan bahwa: Implementasi KA Bandara (Minangkabau Ekpres) Sebagai Sarana Transportasi disimpulkan bahwa Implementasi KA Bandara (Minangkabau Ekpres) Sebagai Sarana Transportasi dengan melaksankaan program pembangunan KA Bandara Minangkabau Ekspres pada tahaun 2012 sampai akhir 2017, pembangunan KA Bandara Internasional Minangkabau (KA BIM) tahun 2012, pada tahun 2015-2016 pembangunan Stasiun Bandara Internasional Minangkabau tahap I dan II. Dengan kisaran anggaran $300 \mathrm{M}$ sampai pada tahun 2030. Penyebab Kurangnya minat Masyarakat naik KA Bandara Minangkabau Ekpres disimpulkan bahwa: (a) Saranan dan Prasarana, kurangnya sarana dalam memenuhi kebetuhan penumpang, (b) Stasiun kereta api tidak terintegrasi dengan angkutan umum lainnya Akses ke stasiun saat ini masih sangat minim, sehingga masyarakat lebih dari dua kali menggunakan moda Transportasi ke stasiun, (c) Promosi KA Bandara belum Maksimal, ketidaktahuannya masyarakat tentang jadwal keberangkatan dan kedatangan KA bandara, hal ini di sebabkan karena pihak pengelola kurang memaksimal media informasi seperti facebook, instagram, dan media sosial lainnya.

Upaya untuk menjadikan KA Minangkabau Ekpres menjadi angkutan Publik disimpulkan bahwa: (a) Memperbaiki Sarana dan Prasarana, melakukan penambahan jalur Kereta dari stasiun simpang Haru menuju Pulau Aie, serta melakukan pembersihan jalur KA yang tidak terpakai agak bisa di gunakan kembali, (b) Menamba stasiun

pemberhentian, dan (c) Meningkatkan Promosi, kedepannnya pihak pengelola akan mengencarkan promosi dengan mengadakan event, memasang spanduk, serta lebih gencar aktif di media sosial karena untuk sekarang di era milenial masyarakat lebih cendrung lebih cepat dapat informasi lewat media sosial, hal ini yang nanti akan di lakukan oleh pihak pengelola kedepannya.

\section{SARAN}

1. Kepada pemerintah, diharapakan agar menmabh gerbong KA bandara dan menambh stasiun, agar akses masyarakat lebih mudah.

2. Kepada pengelola KA bandara Minangkabau agar lebih meningkatkan promosi, agar masyarakat cepat mendapatkan informasi terkait stasiun, keberangkatan, dan harga tikit.

3. Kepuasan Penumpang Kerata Api Bandara Minangkabau dengan fasilitas yang diterima sudah sangat baik, tetapi perlu ditingkatkan kembali terutama fasilitas lainya, tempat ruang tunggu.

4. Kepada peneliti selanjunya, agar melakukan penelitian dengan konsep yang berebda yaitu, melakukan penelitian sarana-dan prasaran kereta api bandara Minangkabau.

\section{UCAPAN TERIMA KASIH}

1. Ibu Dr. Siti Fatimah, M.Pd selaku Dekan Fakultas Ilmu Sosial Universitas Negeri Padang. 
2. Bapak Aldri Frinaldi, SH, M.Hum, Ph.D selaku Ketua Jurusan Ilmu Administrasi Negara Fakultas Ilmu Sosial Universitas Negeri Padang.

3. Bapak Drs Karjuni Dt maani, M.Si selaku Sekretaris Jurusan Ilmu Administrasi Negara Fakultas Ilmu Sosial Universitas Negeri Padang sekaligus pembimbing akademik bagi penulis.

4. Bapak Rahamadani Yusran, M.Si selaku dosen pembimbing yang telah memberikan bimbingan, pengarahan, motivasi, dan waktu yang sangat berharga kepada penulis dalam menyelesaikan skripsi ini.

5. Bapak dan Ibu dosen jurusan Ilmu Administrasi Negara yang sudah memberikan pengetahuan dan wawasan kepada penulis selama melaksanakan kuliah.

6. Teristimewa kepada orang tua penulis yaitu Bapak Sahirman (Alm) dan Ibu Nurayan yang telah memberikan dukungan moral dan materil serta doa yang tulus dan ikhlas kepada penulis

7. Kakak-kakak tercinta,AL-khairi,Riza Desriyanti dan Arma Wiyas yang telah memberikan semangat dan dukungan kepada penulis

8. Spesial terima kasih kepada Aulia Sundari, Witya Tryanti, Resfiana, Yanni Ramadhani, Nurul Fikra, Zakia Ulfa, Dicki Mulya, Ahmad Zakki, Reza Fajriandi, Syukrizal Mulya, Eko Sammara V.T, M. Ilham Wahyudi yang telah banyak membantu dan memberikan semangat dalam menyelesaikan skripsi ini.

\section{DAFTAR PUSTAKA}

\section{Peraturan Perundang- Undangan}

UU No. 23 tahun 2007 tentang Perkertaapian

\section{Buku}

Akbar, Muhamad Firyanti S. IP., M.Si., Widya Kurniati Mohi, S.IP., M.Si.2018.Studi Evaluasi Kebijakan.Gorontalo. Ideas Publishing

Arikunto, Suharsimi dan Jabar, Cepi Safruddin Abdul. 2008. Evaluasi ProgramPendidikan:Pedoman Teoretis Praktis bagi Mahasiswa dan Praktisi Pendidikan: Jakarta: Bumi Aksara.
Dirjen Perkeretaapian Nasional, Dinas Perhubungan.2011. Rencangan Induk Perkeretaapian Nasional (Ripnas:2030).Jakarta Pusat.

Indiahono, Dwiyanton. 2009. Kebijkan Publik Berbasis Dynamic Policy Analysis. Yogyakarta: Grava Media

Sugiyono, 2017. Metode Penelitian Kuantitatif, Kualitatif, Kombinas. Bandung: Alvabeta.

Sugiyono. 2009. Metode Penelitian Kuantitatif Kualitatif dan $R \& D$. Bandung. Alfabeta

\section{Internet}

Bisnis.Com,2018, KA BANDARA MINANGKABAU: Akhirnya Tuntas Meski Sempat Tak Prioritas.

Sindo News.2018, Ini Tarif Kereta Api Minangkabau Ekpres.) $\{21$ mei 2018\}

\section{Jurnal}

Amin \& Swandana. 2017. Alat Pemberi Informasi Pemberhentian Kereta Secara Otomatis Dari Stasiun Tebing TinggiMedan-Tebing Tinggi Berbasis Mikrokontroler ( Automatic Train Station Automobile Dispatching Tool From the Station Tebing Tinggi-MedanTebing Tinggi Microcontroller Based. Journal of Electrical and System Control Engineering). Vol. 1(1) Agustus (2017).

Julien . 2013. Analisis Ability To Pay Dan Willingness To Pay Pengguna Jasa Kereta Api Bandara Kualanamu (Airport Railink Service). Jurnal Ekonomi dan Keuangan. Vol.2 No.3.

Khairunnisa,dkk. 2019. Analisis Harga Tiket Dan Fasilitas Transaksi Terhadap Kepuasan Penumpang Kereta Api Bandara Soekarno Hatta. Jurnal Lentera Bisnis DOI : 10.34127/jrlab.v8i2.292 Volume 8, No 2 November 2019 ISSN Cetak 2252-9993, ISSN Online 2598$618 \mathrm{X}$

Santoso \& Purba. 2015. Pembuatan Aplikasi Pemberi Informasi Pemberhentian Kereta Api Secara Otomatis Berbasis Android. Artikel publikasi rogram Studi Teknik Informatika, Fakultas Teknologi Industri, Universitas Kristen Petra Jl. Siwalankerto 121-131, Surabaya 60236 
Jurnal Ilmiah Mandala Education

http://ejournal.mandalanursa.org/index.php/JIME/index

Terakreditasi Peringkat 4 (No. SK: 36/E/KPT/2019)

Telp. (031)-2983455, Fax. (031)8417658 . 